\title{
HIGH TEMPERATURE APPLICATIONS OF STRUCTURAL CERAMICS
}

QUARTERLY PROGRESS REPORT

$$
\text { January - March } 1981
$$

Samuel J. Schneider

Project Manager

Center for Materials Science National Bureau of Standards U. S. Department of Commerce Washington, D. C. 20234

\section{PREPARED FOR THE UNITED STATES DEPARTMENT OF ENERGY}

\section{Under Contract No. DE-A105-800R20679}

"This report was prepared as an account of work sponsored by the United States Government. Neither the United States nor the United States Department of Energy, nor any of their employees, nor any of their contractors, subcontractors, or their employees, makes any warranty, express or implied, or assumes any legal liability or responsibility for the accuracy, completeness, or usefulness of any information, apparatus, product or process disclosed, or represents that its use would not infringe privately owned rights." 

I. INTRODUCTION. . . . . . . . . . . . . . . . 1

II. DETAILED DESCRIPTION OF TECHNICAL PROGRESS. . . . . . . . . 1

Subtask A. High Temperature Fracture of Structural Ceramics. . 1

Subtask B. Crack Growth Mechanism Maps . . . . . . . . . . 3

Subtask C. Microstructure and Phase Alteration . . . . . . 6

Subtask D. Microstructure and Fracture in Reactive

Environments ............... 7 



\section{NBS-5.2.10 - HIGH TEMPERATURE APPLICATIONS \\ OF STRUCTURAL CERAMICS}

E. R. Fuller, R. J. Fields, T. J. Chuang,

T. A. Hahn and S. J. Schneider

National Bureau of Standards

Center for Materials Science

Washington, D. C. 20234

\section{INTRODUCTION}

The achievement of higher efficiency thermochemical engines and heat recovery systems requires the availability of high temperature, high performance structural materials. Structural ceramics such as SiC, $\mathrm{Si}_{3} \mathrm{~N}_{4}$ and certain $\mathrm{Al}_{2} \mathrm{O}_{3}-\mathrm{Si}_{3} \mathrm{~N}_{4}$ combinations have received particular attention for these applications due to their basic characteristics of good strengths coupled with good corrosion and thermal shock resistances. Even with these positive attributes, improved reliabilities and extended lifetimes under service conditions are necessary for structural ceramics to gain industrial acceptance and use. The problems are mechanical and/or chemical in nature and are enhanced by the fact that these materials are subjected to high temperatures, reactive environments and extreme thermal gradients.

With an objective of improved performance for heat engine/heat recovery applications the NBS program on structural ceramics addresses these problems through the determination of the critical factors which influence mechanical and microstructural behavior. The activities of the program are grouped under four major subtasks with each designed to develop key data, associated test methods and companion predictive models. The status of the subtasks are detailed in the following sections.

NBS 5.2.10(A) - HIGH TEMPERATURE FRACTURE OF STRUCTURAL CERAMICS

RESULTS FROM PRIOR QUARTERS

Four-point bend tests on notched bars of $\mathrm{Si}_{5} \mathrm{AlON}_{7}$ were completed and the results compared with previous work on an yttria-doped silicon nitride (NCX 34) and with literature values for other silicon nitrides. 
The NCX 34 appeared most promising and further tests will be carried out on it and other research grade materials recently received. Reduced scale testing rigs were made to test small billets of experimental materials. The reduced scale testing rigs were fabricated from silicon carbide. These were used to test 15 different compositions of silicon nitride + Y.A.G. (yttrium aluminum garnet) materials (received from Prof. Tien, University of Michigan). The tests were carried out at $1300{ }^{\circ} \mathrm{C}$ as oxidation was too severe at higher temperature for these materials. Further studies of Tien's $\mathrm{Si}_{3} \mathrm{~N}_{4}$ materials were conducted to obtain critical stress intensity factors and to clarify some inconsistencies in earlier results. A sialon specimen received from a Japanese source was annealed at $1430{ }^{\circ} \mathrm{C}$ for 60 hours with little degradation of the specimen. Billets of SiC materials were ordered from Norton Corp. and Carborundum Co. A literature survey of available data on fracture toughness, crack growth behavior, and creep of $\mathrm{SiC}, \mathrm{Si}_{3} \mathrm{~N}_{4}$, and sialon was completed.

\section{DISCUSSION OF CURRENT ACTIVITIES}

\section{Experimental Work}

High temperature four-point bending tests under constant displacement rate conditions have been performed on several $\mathrm{SiC}$ and $\mathrm{Si}-\mathrm{Al}-0-\mathrm{N}$ specimens.

In the case of $\alpha-S i C$ tested in air the results showed negligible oxidation and considerable resistance to slow crack growth even at temperatures up to $150{ }^{\circ} \mathrm{C}$. This preliminary outcome indicates a promising prospect for $\alpha-S i C$ ceramic materials.

For sialon specimens tested whose chemical composition can be expressed by $\mathrm{Si}_{6-2} \mathrm{Al}_{Z}{ }_{2} \mathrm{~N}_{8-Z}$, it was found that as the value $\mathrm{Z}$ increases, the susceptibility to crack growth and oxidation decreases. Thus $\mathrm{Si}_{3} \mathrm{Al}_{3} \mathrm{O}_{3} \mathrm{~N}_{5}$ offers the highest resistance to crack growth and oxidation of all the sialons we have studied at high temperatures. The billets of various SiC ceramic materials ordered previously from Norton Corp. and Carborundum Company have been obtained some of which have been machined into shapes suitable for 4 point bending tests. 
The equation for the stress intensity $\left(\mathrm{K}_{\mathrm{I}}\right)$ under pure bending, which has the form $K_{I}=\sigma \sqrt{\pi a} \mathrm{~F}\left(\frac{a}{b}\right)$, has been investigated in more detail since the accuracy of this expression has direct impact on the outcome of the ongoing experiments. An expression for the function $F$ in terms of the crack length parameter $a / b$ is readily available from the literature in the form of a polynominal, using the least square method which is applicable only in the range of $a / b \leq 0.6$. Although another expression based on trigonometric functions is valid in the whole range of $a / b$, it unfortunately blows-up as a approaches $b$ and thus can not be used directly. However, Wilson's solution which is applicable when a approaches $\mathrm{b}$ shows asymptotic behavior of $\mathrm{F}$ proportional to $\left(1-\frac{a}{b}\right)^{-3 / 2}$. Therefore by plotting $\left(1-\frac{a}{b}\right)^{-3 / 2} \mathrm{~F}$ vs $a / b$ instead of $\mathrm{F}$ vs. $\mathrm{a} / \mathrm{b}$ a finite curve was obtained which can be used to predict a more precise value of $\mathrm{K}$ for a given instantaneous value of crack length.

Other theoretical work that is presently in process concerns the behavior of the load-displacement $(P-\Delta)$ curve. Here, attention is being focused on evaluating the sensitivity of the (P- $\Delta$ ) curve to a given velocitystress intensity factor $(\mathrm{V}-\mathrm{K})$ constitutive relationship. This requires a close investigation of the relation between $(V-K)$ and $(P-\Delta)$ curves and how to predict $(P-\Delta)$ curves for a known $(V-K)$ curve or vice versa. We note that the preceding work on $\mathrm{K}$ will enter the $(\mathrm{V}-\mathrm{K})$ relation as well as $(\mathrm{P}-\Delta)$ curve through the compliance parameters.

\section{NBS 5.2.10(B) - CRACK GROWTH MECHANISM MAPS}

\section{RESULTS FROM PRIOR QUARTERS}

Preliminary maps for $\mathrm{Si}_{3} \mathrm{~N}_{4}$ have been drawn. A computer program for automatically drawing maps from $(\mathrm{V}-\mathrm{K})$ data has been written. Data for SiC has been collected.

Additional data on SiC, particularly static fatigue data, was collected with the aim of constructing a crack growth mechanism map for this material. An evaluation was made of $\mathrm{K}_{\mathrm{IC}}$ as defined by ASTM E-399 because this definition conflicts with common usage in the ceramics literature. 
A preliminary crack growth mechanism map for a commercial, hot pressed SiC material was constructed from published information. The literature survey of fracture and crack growth mechanisms was completed for silicon carbide, silicon nitride, and sialons.

\section{DISCUSSION OF CURRENT ACTIVITIES}

A set of creep crack growth data on $\mathrm{Si}-\mathrm{Al}-0-\mathrm{N}$ tested at $1400^{\circ} \mathrm{C}$ was obtained from the literature (Lewis and Karunaratne, ASTM STP, 1981) and is compared with a crack growth theory we have been developing which is based on diffusion mechanisms. The comparison as illustrated in Fig. B.1 is quite favorable. The theory assumes the existence of a grain boundary crack which is growing in steady state due to externally sustained loads by stress assisted surface and grain-boundary self-diffusion. By further assuming that the mechanical behavior of the grains on both sides of the crack is linear elastic, the theory identifies a crack-tip stress intensity factor $K_{I}$, defined in a sense as though there is no diffusion, as the correct parameter causing the crack to grow. The functional dependence of the crack tip velocity $\mathrm{V}$ on $\mathrm{K}_{\mathrm{I}}$ is described according to the theory by the following equation: $\mathrm{K}_{\mathrm{I}} / \mathrm{K}_{\mathrm{G}}=0.865\left[\left(\mathrm{~V} / \mathrm{V}_{\min }\right)^{1 / 12}+\left(\mathrm{V} / \mathrm{V}_{\min }\right)^{-1 / 12}\right]$ where $\mathrm{K}_{\mathrm{G}}$ is the critical $\mathrm{K}_{\mathrm{I}}$ predicted by Griffith theory and $\mathrm{V}_{\text {min }}$ is "threshold" velocity below which no crack growth is possible (and the corresponding $\mathrm{K}_{\mathrm{I}}$ at that velocity is $1.69 \mathrm{~K}_{\mathrm{G}}$ ). Thus plotting $\mathrm{V} / \mathrm{V}_{\text {min }}$ against $\mathrm{K} / \mathrm{K}_{\mathrm{G}}$, a single curve results regardless of material and temperature. The material and temperature dependences are included in the parameters of $\mathrm{K}_{\mathrm{G}}$ and $\mathrm{V}_{\min }$. The data on Si-Al-0-N are plotted in Fig. B.1 with both an absolute scale and a normalized scale. As can be seen, most data points fall along the curve except the three data points in the lower velocity range which exhibit a different functional dependence perhaps due to excessive blunting of the crack tip.

The above described theory together with its comparison to data is described in a paper entitled, "A diffusive crack growth model for creep fracture". The manuscript is currently being prepared and reviewed for an interagency report and will subsequently be submitted to the Journal of American Ceramic Society for publication. 


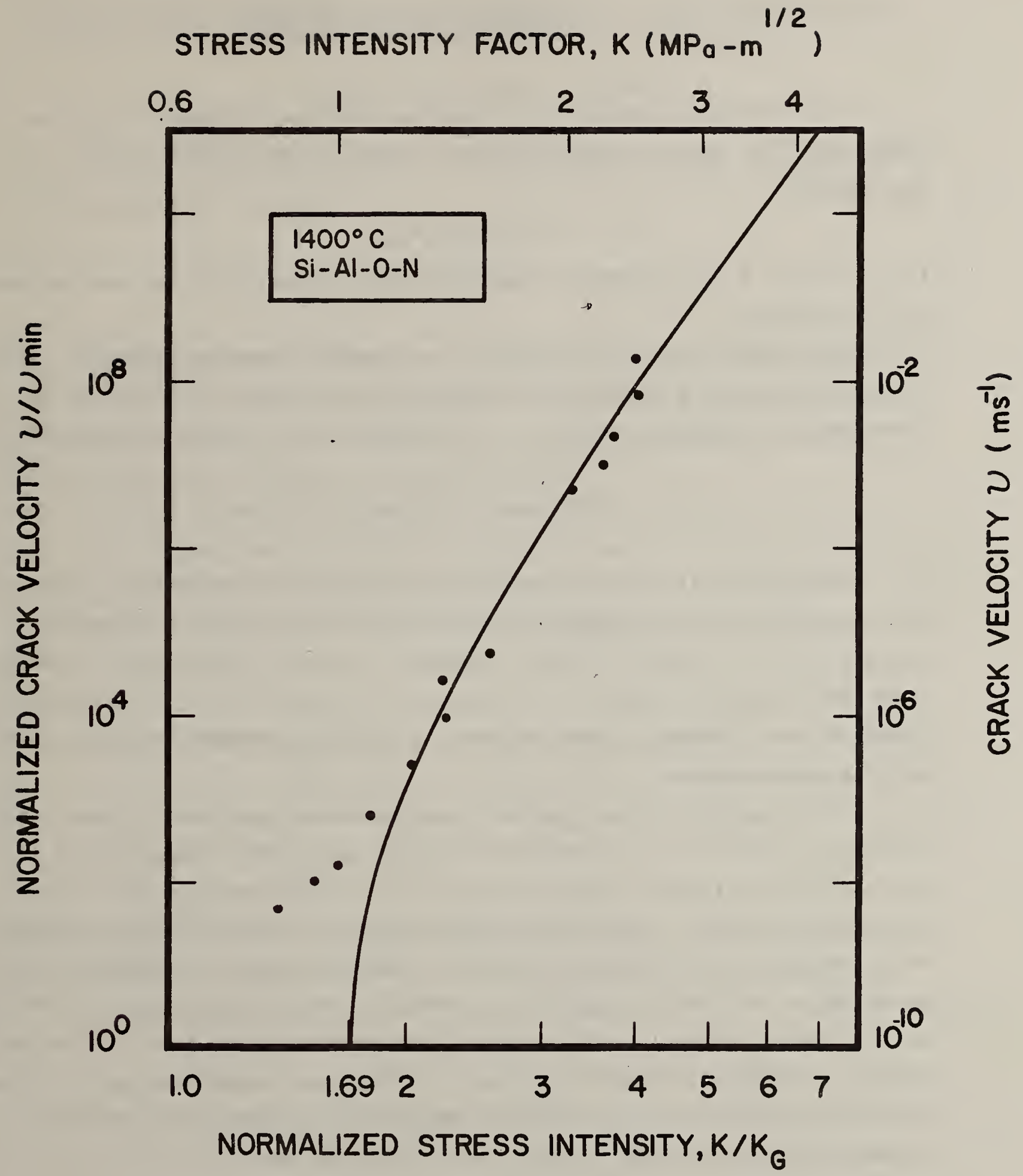

Fig. B:1. Theoretical prediction of $\mathrm{V}-\mathrm{K}$ relationship. Data of creep crack growth in Sialon tested at $1400{ }^{\circ} \mathrm{C}$ are plotted for sake of comparison. 


\section{RESULTS FROM PRIOR QUARTERS}

$\mathrm{X}$-ray analysis of nine sialon samples from the Japanese source was completed. The lattice parameters were shown to vary linearly with $z$ in the formula

$$
\mathrm{Si}_{6-z} \mathrm{Al}_{z} \mathrm{O}^{\mathrm{N}} 8-\mathrm{z}
$$

for $\mathrm{z}$ between 1 and 3 . The various polytypes in the different samples were also identified.

Surface analysis of $\beta-\mathrm{Si}_{3} \mathrm{~N}_{4}+$ garnet samples formulated by Prof. Tien of the University of Michigan has been completed. Phases identified in these samples included $\beta-\mathrm{Si}_{3} \mathrm{~N}_{4}, \quad \beta$ - cristobalite, $\beta-\mathrm{Y}_{2} \mathrm{Si}_{2} \mathrm{O}_{7}$, and mullite.

\section{DISCUSSION OF CURRENT ACTIVITIES}

Current activities have been directed toward the analysis of commercial SiC materials. Multiple samples of Norton's NC 430 and NC 203 have been prepared for the long term, high temperature oxidation exposures. Standard $x$-ray diffraction patterns of SiC have been collected from the 1iterature. These include patterns of the hexagonal polytypes, rhombohedral polytypes, and the cubic material.

$X$-ray analysis of "as received" Carborundum's $\alpha$-SiC showed that it is composed of both the $6 \mathrm{H}$ (H-hexagonal) and $4 \mathrm{H}$ polytypes of $\mathrm{SiC}$. There is also a trace of a phase that could not be identified because of its weak diffraction pattern. Norton's Recrystallized SiC was found to be composed exclusively of the 6H polytype of SiC. Norton's NC 203 is composed of the $6 \mathrm{H}$ polytype but also contains $\mathrm{WC}$, a possible trace of $\mathrm{Al}_{2} \mathrm{O}_{3}$, and a trace of another phase that could not be identified because of its weak diffraction pattern. Analysis of Norton's NC 430 is being carried out currently. The $6 \mathrm{H}$ polytype of SiC and Si have been identified. Another well developed phase is also present but has not been identified as yet.

These samples will be analyzed again after the high temperature fracture test and the long term, high temperature oxidation exposure. 


\section{NBS-5.2.10(D) - MICROSTRUCTURE AND FRACTURE IN REACTIVE ENVIRONMENTS}

RESULTS FROM PRIOR QUARTERS

This is a new subtask which started January 1, 1981. There are no prior quarters to report.

\section{DISCUSSION OF CURRENT ACTIVITIES}

Various alternate systems were considered for an apparatus in which to conduct high temperature mechanical tests under gaseous environments of fossil fuel combustion products. The following decisions have been made concerning the system and its operation:

1. Heating System - $\mathrm{MoSi}_{2}$ element electric furnace has been chosen. A gas furnace was initially considered. Due to limitations on possible gaseous environments, this system was rejected. The electric furnace decided upon will allow a much wider range of gas compositions to be employed.

2. Gaseous Environment System - provided by gas mixing from compressed tank supply. Steam will be obtained either from a steam generator or by bubbling gas composition through water at a specific temperature to give desired vapor pressure.

3. Loading System - A choice will be made between either an existing Instron displacement rate controlled machine or a hydraulic ram coupled to a load cell and specially assembled for the present purpose.

4. Specimen Configuration - Single-edge notched bars will be tested in 3 or 4 point flexural loading. These specimens will be 25 to $50 \mathrm{~mm}$ long and will be used to determine $\mathrm{K}_{I C}$. Double torsion specimen $15 \times 20 \times 2$ up to $25 \times 75 \times 2 \mathrm{~mm}$ will be used for crack velocity measurements. 
